\title{
Adrenaline injection plus argon plasma coagulation versus adrenaline injection plus hemoclips for treating high-risk bleeding peptic ulcers: A prospective, randomized trial
}

\author{
Seyed Alireza Taghavi MD,2, Seyed Mohammad Soleimani MD², Seyed Mohammad Kazem Hosseini-Asl MD ${ }^{1,2}$, \\ Ahad Eshraghian MD¹, Hajar Eghbali MD², Seyed Mohsen Dehghani MD², Bita Ahmadpour MD², \\ Mehdi Saberifiroozi MD ${ }^{1,2}$
}

SA Taghavi, SM Soleimani, SMK Hosseini-Asl, et al. Adrenaline injection plus argon plasma coagulation versus adrenaline injection plus hemoclips for treating high-risk bleeding peptic ulcers: A prospective, randomized trial. Can J Gastroenterol 2009;23(10):699-704.

BACKGROUND/OBJECTIVE: Several combination endoscopic therapies are currently in use. The present study aimed to compare argon plasma coagulation (APC) + adrenaline injection (AI) with hemoclips + AI for the treatment of high-risk bleeding peptic ulcers. METHODS: In a prospective randomized trial, 172 patients with major stigmata of peptic ulcer bleeding were randomly assigned to receive APC + AI $(n=89)$ or hemoclips + AI $(n=83)$. In the event of rebleeding, the initial modality was used again. Patients in whom treatment or retreatment was unsuccessful underwent emergency surgery. The primary end point of rebleeding rate and secondary end points of initial and definitive hemostasis need for surgery and mortality were compared between the two groups.

RESULTS: The two groups were similar in all background variables. Definitive hemostasis was achieved in 85 of 89 (95.5\%) of the APC $+\mathrm{AI}$ and 82 of $83(98.8 \%)$ of the hemoclips + AI group $(\mathrm{P}=0.206)$. The mean volume of adrenaline injected in the two groups was equal (20.7 mL; $\mathrm{P}=0.996)$. There was no significant difference in terms of initial hemostasis $(96.6 \%$ versus $98.8 \% ; \mathrm{P}=0.337$ ), rate of rebleeding $(11.2 \%$ versus $4.8 \% ; \mathrm{P}=0.124)$, need for surgery $(4.5 \%$ versus $1.2 \% ; \mathrm{P}=0.266)$ and mortality $(2.2 \%$ versus $1.2 \% ; \mathrm{P}=0.526)$. When compared for the combined end point of mortality plus rebleeding and the need for surgery, there was an advantage for the hemoclip group ( $6 \%$ versus $15.7 \%, \mathrm{P}=0.042$ ).

CONCLUSION: Hemoclips + AI has no superiority over APC + AI in treating patients with high-risk bleeding peptic ulcers. Hemoclips + AI may be superior when a combination of all negative outcomes is considered.

Key Words: Adrenaline; Argon plasma coagulation; Hemoclips
Injection d'adrénaline plus coagulation au plasma argon versus injection d'adrénaline plus clips hémostatiques dans le traitement des ulcères gastroduodénaux hémorragiques à risque élevé : Étude prospective randomisée

HISTORIQUE/OBJECTIF : Plusieurs techniques endoscopiques combinées sont actuellement utilisées à des fins thérapeutiques. La présente étude visait à comparer la coagulation au plasma argon (CPA) + injection d'adrénaline (IA) aux clips hémostatiques + IA dans le traitement des ulcères gastroduodénaux hémorragiques à risque élevé.

MÉTHODE : Une étude prospective randomisée a regroupé 172 patients porteurs de stigmates majeurs d'ulcères gastroduodénaux hémorragiques et les a assignés aléatoirement soit à la CPA + IA $(\mathrm{n}=89)$ soit aux clips hémostatiques + IA $(\mathrm{n}=83)$. Dans l'éventualité d'une reprise du saignement, la modalité initiale était appliquée de nouveau. Les patients chez qui le traitement ou le retraitement échouait subissaient une chirurgie d'urgence. On a comparé les deux groupes pour ce qui est du paramètre principal, taux de reprise des saignements, et des paramètres secondaires, hémostase initiale et définitive, nécessité de la chirurgie et mortalité.

RÉSULTATS : Les deux groupes étaient similaires pour tout ce qui concerne les variables de départ. L'hémostase définitive a été obtenue chez 85 patients soumis à la CPA + IA sur $89(95,5 \%)$ et chez 82 des patients soumis aux clips hémostatiques + IA sur $83(98,8 \%)(p=0,206)$. Le volume moyen d'adrénaline injecté a été égal dans les deux groupes $(20,7 \mathrm{~mL}, \mathrm{p}=0,996)$. On n'a noté aucune différence significative sur le plan de l'hémostase initiale $(96,6 \%$ vs $98,8 \%, p=0,337)$, du taux de reprise des saignements $(11,2 \%$ vs $4,8 \%, \mathrm{p}=0,124)$, de la nécessité de la chirurgie $(4,5 \%$ vs $1,2 \%, \mathrm{p}=0,266)$ et de la mortalité $(2,2 \%$ vs $1,2 \%$, $\mathrm{p}=0,526)$. Comparativement au paramètre mixte mortalité plus reprise du saignement et nécessité de la chirurgie, on a noté un avantage dans le groupe soumis aux clips hémostatiques ( $6 \%$ vs $15,7 \%, \mathrm{p}=0,042$ ).

CONCLUSION : Les clips hémostatiques + IA ne sont pas révélés supérieurs à la CPA + IA dans le traitement des patients souffrant d'ulcères gastroduodénaux hémorragiques à risque élevé. Cette modalité pourrait toutefois se révéler supérieure lorsque l'on tient compte de tous les paramètres négatifs à la fois.

Mortality is related to age, comorbidity, endoscopic stigmata and rebleeding as well as the degree of the initial bleeding, transfusion volume and rebleeding after endoscopic therapy (6-9).

Endoscopic therapy has generally been recommended as the first-line treatment for upper gastrointestinal bleeding because it has been shown to reduce recurrent bleeding, the need for surgery and mortality (10). The American Society of Gastrointestinal Endoscopy guidelines (11) and the United to $10 \%$, either directly caused by the bleeding episode or through deterioration of concurrent medical illnesses $(4,5)$.

${ }^{1}$ Gastroenterohepatology Research Centre, Nemazee Hospital; ${ }^{2}$ Division of Gastroenterology, Department of Internal Medicine, Shiraz University of Medical Sciences, Shiraz, Iran

Correspondence: Dr Seyed Alireza Taghavi, Department of Internal Medicine, Nemazee Hospital, PO Box 71345-1744, Shiraz, Iran Telephone 98-711-62762, fax 98-711-6276212, e-mail ataghavi@sums.ac.ir

Received for publication May 18, 2009. Accepted July 9, 2009 
Kingdom guidelines (12) stated that no single modality has been shown to be superior for treating upper gastrointestinal bleeding caused by peptic ulcer disease and that hemoclips are particularly useful for actively bleeding large vessels, but they may be difficult to apply to awkwardly located ulcers. The Nonvariceal Upper GI Bleeding Consensus Conference Group, which consisted mostly of Canadian experts, proposed the most definitive recommendations: "no single method of endoscopic injection is superior to the others, no single method of endoscopic thermal coaptive therapy is superior to the others and the placement of clips is a promising endoscopic hemostasis therapy for high-risk stigmata" (13).

Argon plasma coagulation (APC) is a new method that offers controlled, noncontact electrocoagulation. APC has proven to be safe and effective for coagulation of tissue to achieve hemostasis (14). It can be learned easily, is repeatable and induces limited tissue destruction (6). On the other hand, the depth of injury is unpredictable and may produce only shallow coagulation, which is insufficient for hemostasis (14).

There are variable success rates reported in the literature regarding hemostasis using endoscopic clips or APC, and studies comparing clips or APC with other endoscopic treatment modalities have yielded conflicting results. Most studies using clips or APC have been limited by relatively small sample sizes, variations in study design, and entry and outcome criteria. The endoscopic techniques used were also dissimilar in that some combined clips or APC with injection whereas others used clips or APC alone in actively bleeding ulcers (15-17).

We conducted a randomized controlled trial to compare the efficacy and safety of endoscopic combination therapy using $\mathrm{APC}$ plus adrenaline injection (AI), with hemoclips plus AI.

\section{METHODS}

\section{Patients}

A prospective, randomized, comparative trial was conducted between March 2007 and June 2008, in medical centres affiliated with the Shiraz University of Medical Science, Shiraz, Iran. All patients with signs of upper gastrointestinal bleeding underwent endoscopy within $12 \mathrm{~h}$ of admission. Men and women older than 18 years of age were eligible for inclusion in the study if endoscopy showed a gastric or duodenal ulcer with an actively bleeding vessel (spurting or oozing), a nonbleeding visible vessel or an adherent clot. For those with a nonbleeding visible vessel, coffee-ground material or blood in the stomach and/or duodenum, hemodynamic instability or an initial hemoglobin level of less than $100 \mathrm{~g} / \mathrm{L}$, endoscopy was required to show recent bleeding. Exclusion criteria included having a platelet count of less than $50 \times 10^{9} / \mathrm{L}$, an international normalized ratio of greater than 2, gastric malignancy, multiple bleeding sites or previous gastrectomy.

The clinical characteristics (age, sex, blood pressure, comorbid diseases, use of nonsteroidal anti-inflammatory drugs, smoking status, history of peptic ulcer disease or upper gastrointestinal bleeding) of each patient were recorded.

Randomization was performed at the time of endoscopy by means of numbered, sealed envelopes containing treatment assignments randomly generated by computer. All endoscopic hemostatic procedures were performed by two experienced endoscopists who did not participate in the postprocedure care of the patients.

\section{Procedure}

Adrenaline (1:10,000 dilution) in $0.5 \mathrm{~mL}$ or $1 \mathrm{~mL}$ doses was injected through multiple punctures into and around the bleeding site, with at least $10 \mathrm{~mL}$ being injected. After AI, patients in the APC group underwent treatment with an argon plasma coagulator unit (APC 2, VIO 300 D, Erbe, Germany). The spray mode was used with two power/gas settings for gastric and duodenal ulcers $(70 \mathrm{~W}$ and $40 \mathrm{~W}$ and $2 \mathrm{~L} / \mathrm{min}$ to $1 \mathrm{~L} / \mathrm{min}$, respectively). Suction was applied to remove smoke and prevent overinflation of the gastrointestinal tract. Endoscopic hemoclip therapy was performed with stainless steel hemoclips (HX-610-135, Olympus Medical Systems, Japan). Hemoclips were applied with a clip application device (HX-110LR, Olympus, Japan) passed through the $2.8 \mathrm{~mm}$ diameter accessory channel of a standard endoscope. Hemoclips were individually loaded and deployed. For ulcers with clots, the base of the clot was manually irrigated with a $50 \mathrm{~mL}$ syringe $(200 \mathrm{~mL}$ of water total).

After hemostasis was achieved, the bleeding site was observed for at least $4 \mathrm{~min}$. Initial hemostasis was defined as the absence of endoscopic evidence of bleeding during 4 min of observation after therapy. Following therapeutic endoscopy, patients were observed closely. While the patient was in the hospital, treatment included intravenous administration of pantoprazole ( $80 \mathrm{mg}$ stat, $8 \mathrm{mg} / \mathrm{h}$ ) for one day, started on arrival to hospital before endoscopic intervention. Subsequently, oral therapy with omeprazole $20 \mathrm{mg}$ twice daily was started. Endoscopy was performed one day after initial hemostasis, with five biopsy specimens being obtained from the ulcer margin and base. The specimens were evaluated for the presence of malignancy and Helicobacter pylori infection. Individuals who were positive for $\mathrm{H}$ pylori infection, detected by histology, received appropriate eradication therapy. Evidence of recurrent bleeding included new hematemesis, aspiration of fresh blood from a nasogastric tube or continuous melena, with a pulse rate greater than 100 beats/min, a decrease in systolic blood pressure exceeding $30 \mathrm{mmHg}$ or a decrease in hemoglobin of at least $20 \mathrm{~g} / \mathrm{L}$. A second endoscopy was performed in patients who displayed any evidence of recurrent bleeding, with the same endoscopic hemostatic treatment being performed.

Definitive hemostasis was defined as the absence of recurrent bleeding during the 30-day period following initial or secondary endoscopic hemostasis. The rate of recurrent bleeding, as a primary outcome, was compared between the two groups. The rate of initial hemostasis, definitive hemostasis, need for emergency surgery and bleeding-related deaths were compared as secondary outcomes.

Following discharge, patients were requested to return to the outpatient clinic two and four weeks after initial hemostasis. Individuals who did not revisit the outpatient clinic were followed by telephone.

\section{Statistical analysis}

With the assumption that the hemoclip + AI combination method would lower the expected risk of recurrent bleeding from $17 \%$ (18) after APC + AI to 3.8\% (19), 81 patients would have been needed in each group for a power of $80 \%$ and a significance level of 0.05 . Continuous data are summarized as mean (95\% CI). The Student's $t$ test was used to compare the mean values of continuous variables, and the $\chi^{2}$ test was used 


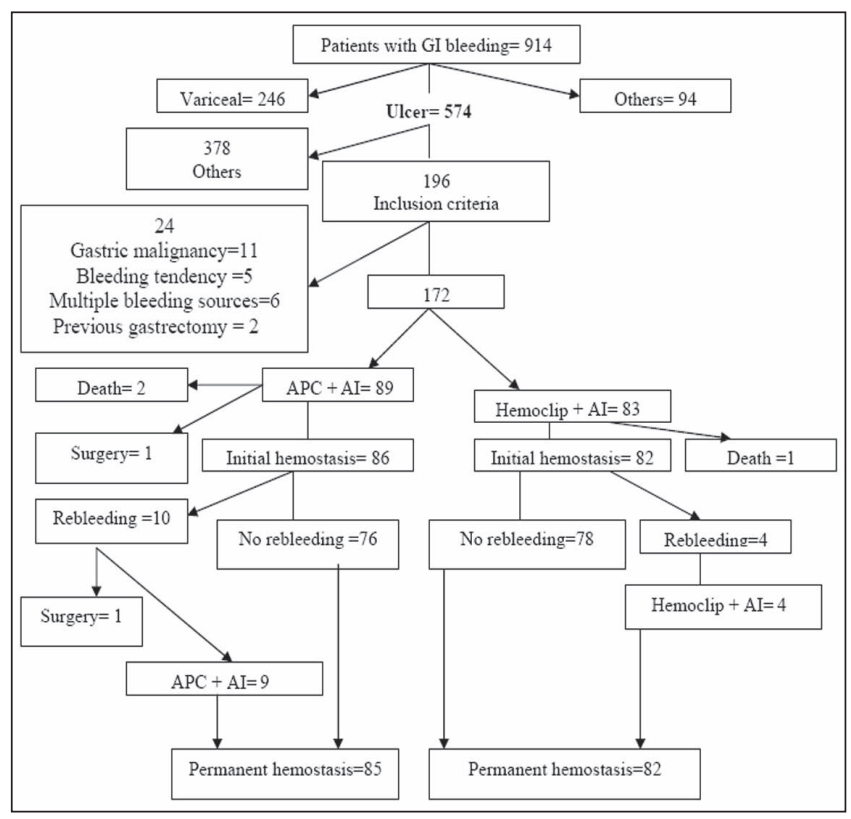

Figure 1) Flow diagram of the study, showing outcomes for all patients. AI Adrenaline injection; APC Argon plasma coagulation; GI Gastrointestinal
TABLE 2

Ulcer characteristics

\begin{tabular}{lccc}
\hline & \multicolumn{2}{c}{ Adrenaline injection } & \\
\cline { 2 - 3 } & With APC & With hemoclips & P \\
\hline Duodenal ulcers & $53(59.6)$ & $38(45.8)$ & 0.71 \\
Anterior & $33(62.3)$ & $21(55.3)$ & \\
Posterior & $15(28.3)$ & $12(31.6)$ & \\
Superior & $1(1.9)$ & 0 & \\
Inferior & $3(5.7)$ & $5(13.2)$ & \\
D2 & $1(1.9)$ & 0 & \multirow{2}{*}{0.71} \\
Gastric ulcers & $36(40.4)$ & $45(54.2)$ & \\
Antrum/Incisura & $7(19.5)$ & 0 & \\
Lesser curvature & $14(38.9)$ & $33(73)$ & \\
Fundus and body & $5(13.9)$ & $5(11.1)$ & \\
Cardia & $10(27.8)$ & $7(15.6)$ & \\
Ulcer type & & & \\
Spurting artery & $9(10.1)$ & $7(8.4)$ & \\
Oozing & $2(2.2)$ & $3(3.6)$ & \\
Visible vessel & $69(77.5)$ & $61(73.5)$ & \\
Adherent clot & $9(10.1)$ & $12(14.5)$ & \\
Ulcer size & & & \\
$<10 \mathrm{~mm}$ & $36(41.6)$ & $44(53)$ & \\
$10 \mathrm{~mm}$ to 20 mm & $40(44.9)$ & $32(38.6)$ & \\
$>$ 20 mm & $12(13.5)$ & $7(8.4)$ & \\
\hline
\end{tabular}

Data presented as $n(\%)$ unless specified otherwise. APC Argon plasma coagulation

TABLE 1

Baseline characteristics of the study groups

\begin{tabular}{|c|c|c|c|}
\hline \multirow[b]{2}{*}{ Characteristic } & \multicolumn{2}{|c|}{ Adrenaline injection } & \multirow[b]{2}{*}{$\mathbf{P}$} \\
\hline & With argon plasma coagulation & With hemoclips & \\
\hline Age, years (mean $\pm S D)$ & $48.63 \pm 15.97$ & $51.34 \pm 14.01$ & 0.24 \\
\hline Sex (males/females), $n / n$ & $73 / 16$ & $60 / 23$ & 0.128 \\
\hline Smoking & $39(36)$ & $46(55.4)$ & 0.01 \\
\hline Nonsteroidal anti-inflammatory drug use & $46(51.7)$ & $33(39.8)$ & 0.117 \\
\hline Hypovolemic shock & $2(2.2)$ & $3(3.6)$ & 0.467 \\
\hline Previous ulcer bleeding & $7(7.9)$ & $5(6)$ & 0.636 \\
\hline Admitted for ulcer bleeding & $85(95.5)$ & $82(98.8)$ & 0.206 \\
\hline In-hospital bleeding & $4(4.5)$ & $1(1.2)$ & 0.206 \\
\hline Duration of admission, days (mean $\pm S D$ ) & $5.34 \pm 1.56$ & $5.52 \pm 1.19$ & 0.396 \\
\hline Helicobacter pylori-positive & $65(73)$ & $63(75.9)$ & 0.288 \\
\hline
\end{tabular}

Data presented as $n$ (\%) unless specified otherwise

for the comparison of categorical variables. The analyses were performed with SPSS version 11.5 (SPSS Inc, USA) for Windows (Microsoft Corporation, USA). A $\mathrm{P}<0.05$ was considered to be statistically significant.

Ethics and consent

Possible complications of endoscopic treatment were discussed with the patients and their relatives, and written informed consent was obtained before trial entry. The present study was approved by the Research Council Ethics Committee of the Shiraz University of Medical Science. The present study was conducted in accordance with the Declaration of Helsinki (Edinburgh revision, 2000).

\section{RESULTS}

A total of 914 patients with upper gastrointestinal bleeding underwent emergency endoscopy. Of these, 574 had ulcer disease,
246 had esophageal or gastric variceal bleeding and 94 had nonulcer lesions. Peptic ulcers with an actively bleeding vessel (spurting or oozing), nonbleeding visible vessels or adherent clots were found in 196 patients. Twenty-four subjects were excluded because of previous gastrectomy, bleeding diathesis, gastric malignancy or multiple bleeding sources at endoscopy (Figure 1).

Clinical data for the patients at study entry are presented in (Table 1). There were no significant differences between the two groups with respect to age, sex, shock state, comorbid diseases, use of nonsteroidal anti-inflammatory drugs, $H$ pylori status and history of previous upper gastrointestinal bleeding.

In the evaluation of smoking, the difference between the groups was significant $(\mathrm{P}=0.01)$, with a greater proportion in the hemoclips + AI group. History of peptic ulcer disease was also significantly higher in the APC + AI group $(\mathrm{P}=0.05)$. Ulcer characteristics (Table 2) were comparable between the study groups. 
TABLE 3

Clinical results

\begin{tabular}{|c|c|c|c|}
\hline & \multicolumn{2}{|c|}{ Adrenaline injection } & \multirow[b]{2}{*}{$\mathbf{P}$} \\
\hline & With APC & With hemoclips & \\
\hline Initial hemostasis, n (\%) & $86(96.6)$ & $82(98.8)$ & 0.337 \\
\hline Rebleeding, n (\%) & $10(11.2)$ & $4(4.8)$ & 0.124 \\
\hline Duodenal ulcer & $1 / 53$ & $2 / 38$ & 0.569 \\
\hline Anterior & $0 / 33$ & $1 / 21$ & \\
\hline Posterior & $1 / 15$ & $1 / 12$ & \\
\hline Superior & 0 & 0 & \\
\hline Inferior & 0 & 0 & \\
\hline Gastric ulcer & $9 / 36$ & $2 / 45$ & 0.01 \\
\hline Antrum/incisura & 0 & 0 & \\
\hline Lesser curvature & $5 / 14$ & $2 / 33$ & \\
\hline Fundus and body & $1 / 5$ & $0 / 5$ & \\
\hline Cardia & $3 / 10$ & $0 / 7$ & \\
\hline \multicolumn{4}{|l|}{ Ulcer type } \\
\hline Spurting artery & $2 / 9$ & $0 / 7$ & \\
\hline Oozing & $0 / 2$ & $0 / 3$ & \\
\hline Visible vessel & $7 / 69$ & $4 / 61$ & \\
\hline Adherent clot & $1 / 9$ & $0 / 12$ & \\
\hline \multicolumn{4}{|l|}{ Ulcer size } \\
\hline$<10 \mathrm{~mm}$ & $4 / 36$ & $1 / 44$ & \\
\hline $10 \mathrm{~mm}$ to $20 \mathrm{~mm}$ & $5 / 40$ & $3 / 32$ & \\
\hline$>20 \mathrm{~mm}$ & $1 / 12$ & $0 / 7$ & \\
\hline Definite hemostasis, n (\%) & $85(95.5)$ & $82(98.8)$ & 0.206 \\
\hline Need for surgery, n (\%) & $2(2.2)$ & 0 & 0.266 \\
\hline Mortality, n (\%) & $2(2.2)$ & $1(1.2)$ & 0.526 \\
\hline
\end{tabular}

There was no statistically significant difference in terms of ulcer sites (stomach versus duodenum), ulcer size, bleeding stigmata or the specific location of ulcers within the stomach and duodenum. Clinical outcome data are summarized in (Table 3).

The mean volume of adrenaline used in the two groups was equal $(20.7 \mathrm{~mL} ; \mathrm{P}=0.996)$. In the $\mathrm{APC}+\mathrm{AI}$ group, the mean $( \pm \mathrm{SD})$ number of APC pulses was $2.75 \pm 0.64$, and the mean number of hemoclips in the hemoclips + AI group was $2.43 \pm 0.72$.

Initial hemostasis was successfully achieved in $96.6 \%$ of the APC + AI group and $98.8 \%$ of the hemoclip + AI group $(\mathrm{P}=0.337)$. In the APC + AI group, two of three patients with uncontrolled bleeding died and one had successful emergency surgery. In the hemoclip + AI group, the only patient with uncontrolled bleeding died before undergoing surgery due to severe hemodynamic instability, similar to the two deaths in the APC + AI group.

Bleeding recurred in 10 patients in the APC + AI group $(11.0 \%)$ and in four of the hemoclip + AI group (4.8\%) $(\mathrm{P}=0.124)$. All 14 of these patients underwent the same repeated endoscopic intervention. Only one patient in the $\mathrm{APC}+\mathrm{AI}$ group needed surgery due to failed endoscopic intervention. Need for surgery $(2.2 \%$ in the APC + AI group versus $0 \%$ in the hemoclip + AI group; $\mathrm{P}=0.266)$ and mortality $(2.2 \%$ in the APC + AI group versus $1.2 \%$ in the hemoclip + AI group; $\mathrm{P}=0.526$ ) was not statistically different. Also, there was not a significant difference between the two groups in achieving definite hemostasis (95.5\% in the APC + AI group versus $98.8 \%$ in the hemoclip + AI group; $\mathrm{P}=0.206$ ) and mean length of hospital stay (5.34 days for the APC + AI group versus 5.52 days for the hemoclip + AI group; $\mathrm{P}=0.396$ ).

When the two groups were compared for the combined end point of mortality plus rebleeding and the need for surgery, there was an advantage to hemoclips, with a slight margin of significance ( $6 \%$ versus $15.7 \%$ for hemoclips and APC groups, respectively, $\mathrm{P}=0.042$ )

No major procedure-related complication (eg, perforation or worsening of bleeding as a result of the hemostatic procedure) was observed in either group.

\section{DISCUSSION}

Endoscopic injection therapy is still commonly used for the treatment of bleeding peptic ulcers, with dilute adrenaline being among the most frequently used solutions. Although this technique can successfully stop the majority of ulcer bleeds, recurrent bleeding still occurs in 10\% to 30\% of cases (2).

Bleeding recurrence has been identified as the most important prognostic factor of mortality (20). Therefore, if recurrence of bleeding can be prevented, the rate of mortality from ulcer bleeding can potentially be reduced (21).

It is generally accepted that the combination of injection therapy with another method of hemostasis (eg, injection therapy + heater probe, injection therapy + hemoclips) is superior to injection therapy alone for definitive control of bleeding, especially in high-risk ulcers $(19,22)$.

The main question for the practicing clinician is, therefore, the most suitable 'type' of combination therapy for the treatment of a high-risk, bleeding peptic ulcer.

Presently, both APC and clipping are commonly used worldwide for the treatment of high-risk bleeding peptic ulcers, both usually used in combination with injection therapy. There are, however, little data available to allow for the comparison of these two methods, and there are arguments in favour of each.

Animal studies have shown that only mechanical methods such as hemoclips may be effective in controlling bleeding for vessels larger than $2 \mathrm{~mm}$ in diameter (23). Tissue damage is minimized with this method (24).

In a meta-analysis performed by Sung et al (25), the pooled data from 15 studies indicated that endoscopic clipping, with or without injection, is more effective than endoscopic injection alone for the treatment of bleeding peptic ulcers, and at least as effective as thermal therapies for the induction of hemostasis and prevention of surgery and mortality.

APC, on the other hand, is easier to target to the bleeding sites than hemoclips (26-28). Despite promising efficacy for the treatment of angiodysplasia, gastric antral vascular ectasia and radiation proctitis, there are few published trials regarding the efficacy of APC for bleeding peptic ulcers. The available data indicate a similar efficacy as heater probe in terms of initial hemostasis as well as recurrent bleeding, and a potential superiority in the speed of initial hemostasis $(18,29,30)$.

The present head-to-head study compared APC and hemoclips in a randomized controlled trial. A high rate of initial hemostasis was achieved in both treatment groups. As expected, ulcers with visible vessels had the highest frequency of recurrent bleeding. A lower rate of recurrent bleeding was noted in gastric ulcers in the hemoclip + AI group than in the APC + 
AI group, although these differences were not statistically significant.

There was also no difference with respect to the predetermined end points of definitive hemostasis $(95.5 \%$ versus $98.8 \% ; \mathrm{P}=0.206)$, need for surgery $(2.2 \%$ versus $0 \% ; \mathrm{P}=0.266)$ and mortality $(2.2 \%$ versus $1.2 \% ; \mathrm{P}=0.526)$, which indicate a similar efficacy for both methods based on the present data. Therefore, clinicians may choose the method based on availability, experience and the clinical situation.

The statistically significant advantage of hemoclips over APC for the combined end point of rebleeding, need for surgery and mortality is interesting, and may suggest a potential trend for the superiority of hemoclips, at least in some subgroups of bleeding peptic ulcers. This, however, can only be confirmed in studies with a larger number of patients. It is also notable that hemoclips were able to stop bleeding in all patients who rebled after the intial application; this may translate to lower mortality in a larger number of patients, considering that the majority of deaths in peptic ulcer bleeding occur in those who rebleed. Hemoclips may also have a viable role as a rescue treatment for rebleeding following other methods of hemostasis.

Larger studies may also be able to elucidate possible differences between these two treatment methods for different subgroups of patients (eg, different vessel size, different locations), which could not be stratified in the current study due to the number of patients.

The application of hemoclips to the posterior part of the duodenum and lesser curvature of the stomach is theoretically difficult. In the present study, difficulties were encountered in the application of hemoclips to the posterior wall of the duodenum in three of $12(25 \%)$ patients and to the lesser curvature of the stomach in seven of 33 (21\%) patients; however, all of these patients achieved initial hemostasis. Although APC has a theoretical advantage in the above mentioned areas (because of the potential for tangential application), the present study demonstrated a lower rebleeding rate in the hemoclips + AI group in the lesser curvature compared with the APC + AI group; however, these differences were not statistically significant. These intriguing results may need further studies to be confirmed.

It may be surprising that despite a limited depth of penetration, APC was shown to be effective for the treatment of bleeding from large vessels in the present trial. Although the actual mechanism of efficacy cannot be determined without a microscopic study of the application site, a combination of compression from inflammation in the burned surrounding tissues as well as possible thrombosis of the involved vessel due to vessel wall damage may be able to explain the efficacy of APC in this subgroup.

The risk of perforation after APC is a matter of debate (10,31-35) and is estimated to be approximately $0.31 \%$ (30). Although this potential risk may be regarded as a disadvantage for APC compared with hemoclips (which induce less demonstrable tissue damage), no perforation was encountered in either of the groups to substantiate this disadvantage in the present study.

No report of bloating or abdominal discomfort (which may be caused by the high gas flow with APC) was reported in either of the groups.

\section{CONCLUSION}

There is no statistically significant superiority for either APC or hemoclips regarding the end points of mortality, need for surgery and rebleeding based on data from the present study.

ACKNOWLEDGEMENT: This study was supported by the Gastroenterohepatology Research Centre of the Shiraz University of Medical Sciences, Shiraz, Iran. The authors appreciate the cooperation of the endoscopy staff of the Nemazee hospital, Shiraz, Iran.

FUNDING: This study was supported by a grant from the Research Council of the Shiraz University of Medical Sciences, Shiraz, Iran.

\section{REFERENCES}

1. Blatchford O, Davidson LA, Murray WR, Blatchford M, Pell J. Acute upper gastrointestinal hemorrhage in west of Scotland: Case ascertainment study. BMJ 1997;315:510-4.

2. Longstreth GF. Epidemiology of hospitalization for acute upper gastrointestinal hemorrhage: A population-based study. Am J Gastroenterol 1995;90:206-10.

3. Vreeburg EM, Snel P, de Bruijne JW, Bartelsman JF, Rauws EA, Tytgat GN. Acute upper gastrointestinal bleeding in the Amsterdam area: Incidence, diagnosis and clinical outcome. Am J Gastroenterol 1997;92:236-43.

4. Rockall TA, Logan RF, Devlin HB, Northfield TC. Incidence of and mortality from acute upper gastrointestinal hemorrhage in the United Kingdom. Steering Committee and members of the National Audit of Acute Upper Gastrointestinal Hemorrhage. BMJ 1995;311:222-6.

5. Targownik LW, Nabalamba A. Trends in management and outcomes of acute non-variceal upper gastrointestinal bleeding: 1993-2003. Clin Gastroenterol Hepatol 2006;4:1459-66.

6. Khan K, Schwarzenberg SJ, Sharp H, Weisdorf-Schindele S. Argon plasma coagulation: Clinical experience in pediatric patients. Gastrointest Endosc 2003;57:110-2.

7. Kim HG, Park JK, Jung YD. Risk factors for early rebleeding after initial endoscopic hemostasis in patients with bleeding peptic ulcers. Gastrointest Endosc 2000;51:208.

8. Lau JY, Sung JJ, Lam YH, et al. Endoscopic retreatment compared with surgery in patients with recurrent bleeding after initial endoscopic control of bleeding ulcers. N Eng J Med 1999;340:751-6.

9. Fallah MA, Prakash C, Edmundowicz S. Acute gastrointestinal bleeding. Med Clin North Am 2000;84:1183-208.

10. Cook DJ, Guyatt GH, Salena BJ, Laine LA. Endoscopic therapy for acute non-variceal hemorrhage: A meta-analysis. Gastroenterology 1992;102:139-48.

11. American Society of Gastrointestinal Endoscopy. Guideline: The role of endoscopy in acute non-variceal upper GI hemorrhage. Gastrointest Endosc 2004;60:497-504.

12. Palmer KR. Non-variceal upper gastrointestinal hemorrhage: Guideline. Gut 2002;51:1-6.

13. Barkun A, Bardou M, Marshall JK, for the Nonvariceal Upper GI Bleeding Consensus Conference Group. Consensus recommendation for managing patients with nonvariceal upper gastrointestinal bleeding. Ann Intern Med 2003;139:843-57.

14. Grund KE, Farin G. Annual of Gastrointestinal Endoscopy. 10th edn. London: Rapid Science, 1997.

15. Chou YC, Hsu PI, Lai KH, et al. A prospective, randomized trial of endoscopic hemoclip placement and distilled water injection for treatment of high-risk bleeding ulcers. Gastrointest Endosc 2003;57:324-8.

16. Lin HJ, Perng CL, Sun IC, Tseng GY. Endoscopic haemoclip versus heater probe thermocoagulation plus hypertonic salineepinephrine injection for peptic ulcer bleeding. Digest Liver Dis 2002;35:898-902.

17. Saltzman JR, Strate LL, Di Sena V, et al. Prospective trial of endoscopic clips versus combination therapy in upper GI bleeding. Am J Gastroenterol 2005;100:1503-8.

18. Cipolletta L, BiancoMA, Rotondano G, Piscopo R, Prisco A, Garofano ML. Prospective comparison of argon plasma coagulator and heater probe in the endoscopic treatment of major peptic ulcer bleeding. Gastrointest Endosc 1998;48:191-5. 
19. Lo CC, Ping I, Lo GH. Comparison of hemostatic efficacy for epinephrine injection alone and injection combined hemoclip therapy in treating high risk bleeding peptic ulcers. Gastrointest Endosc 2006;63:767-73.

20. Turner IB, Jones M, Piper DW. Factors influencing mortality from bleeding peptic ulcers. Scand J Gastroenterol 1991;26:661-6.

21. Brullet E, Campo R, Calvet X, Coroleu D, Rivero E, Simo Deu J. Factors related to the failure of endoscopic injection therapy for bleeding gastric ulcer. Gut 1996;43:111-6.

22. Chung SS, Lau JY, Sung JJ, et al. Randomized comparison between adrenaline injection alone and adrenaline injection plus heater probe treatment for actively bleeding ulcers. BM] 1997;314:1307-11.

23. Hepworth CC, Kadirkamanathan SS, Gong G, Swain CP. A randomized controlled comparison of injection, thermal and mechanical endoscopic methods of hemostasis on mesenteric vessels. Gut 1998;42:462-9.

24. Yuan Y, Wang C, Hunt RH. Endoscopic clipping for acute nonvariceal upper-GI bleeding: A meta-analysis and critical appraisal of randomized controlled trials. Gastrointest Endosc 2008;68:339-51.

25. Sung JJ, Tsoi KK, Lai LH, Wu JC, Lau JY. Endoscopic clipping versus injection and thermo-coagulation in the treatment of nonvariceal upper gastrointestinal bleeding: A meta-analysis. Gut 2007;56:1364-73.

26. Grund KE, Storek D, Farin G. Endoscopic argon plasma coagulation (APC) first clinical experiences in flexible endoscopy. Endosc Surg Allied Technol 1994;2:42-6.
27. Canard JM, Vedrenne B. Clinical application of argon plasma coagulation in gastrointestinal endoscopy: Has the time come to replace the laser? Endoscopy 2001;33:353-7.

28. Farin G, Grund KE. Technology of argon plasma coagulation with particular regard to endoscopic applications. Endosc Surg Allied Technol 1994;2:71-7.

29. Chau CH, Siu WT, Law BKB, et al. Randomized controlled trial comparing epinephrine injection plus heat probe coagulation versus epinephrine injection plus argon plasma coagulation for bleeding peptic ulcers. Gastrointest Endosc 2003;57:455-61.

30. Havanond C, Havanond P. Argon plasma coagulation therapy for acute non-variceal upper gastrointestinal bleeding (review). Cochrane Database Syst Rev 2005;18:CD003791.

31. Grund KE, Zindel C, Farin G. Agron plasma coagulation through a flexible endoscope. Evaluation of a new therapeutic method after 1606 uses. Deutche Medizinische Wochenschrift 1997;122:432-8.

32. Sugawa C, Takekuma Y, Lucas CE, et al. Experimental studies of thermal therapy for severe non-variceal bleeding in dogs. Surg Endosc 1999;13:1203-7.

33. Hoyer N, Thouet R, Zellweger U. Massive pneumoperioneum after endoscopic argon plasma coagulation. Endoscopy 1998;30:934.

34. Norton ID, Wang L, Levine SA, et al. In vivo characterization of colonic thermal injury caused by argon beam coagulation. Gastrointest Endosc 2002;55:631-6.

35. Norton ID, Wang L, Levine SA, et al. Efficacy of colonic submucosal saline solution injection for the reduction of iatrogenic thermal injury. Gastrointest Endosc 2002;56:95-9. 


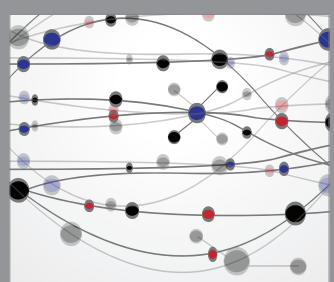

The Scientific World Journal
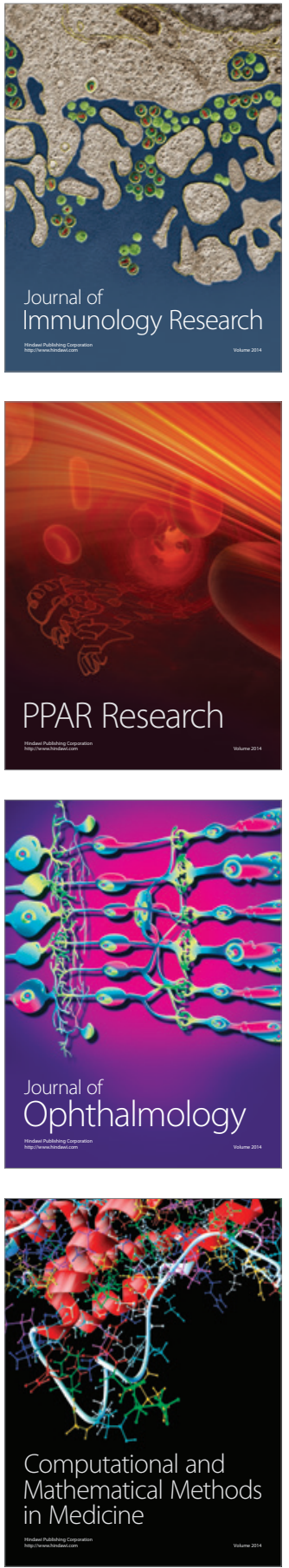

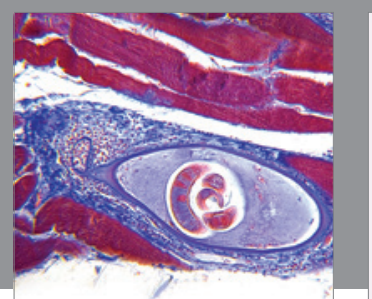

Gastroenterology Research and Practice

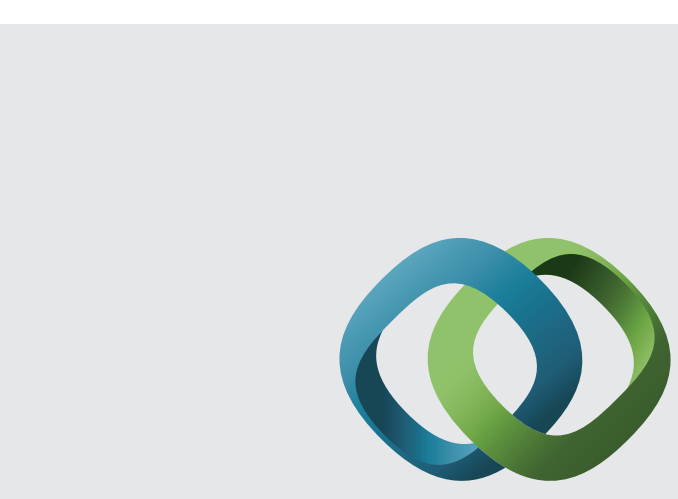

\section{Hindawi}

Submit your manuscripts at

http://www.hindawi.com
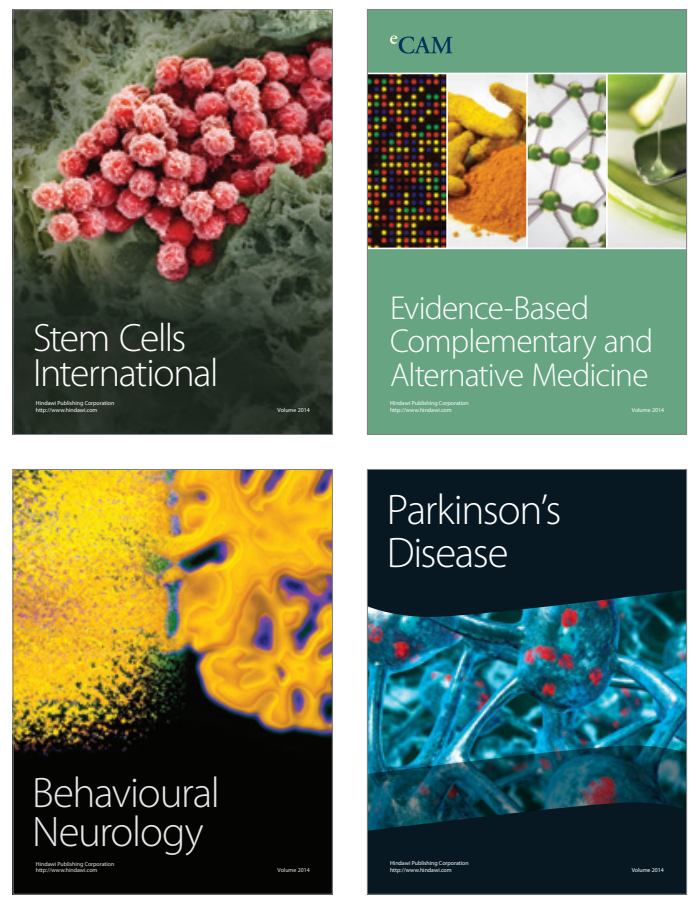
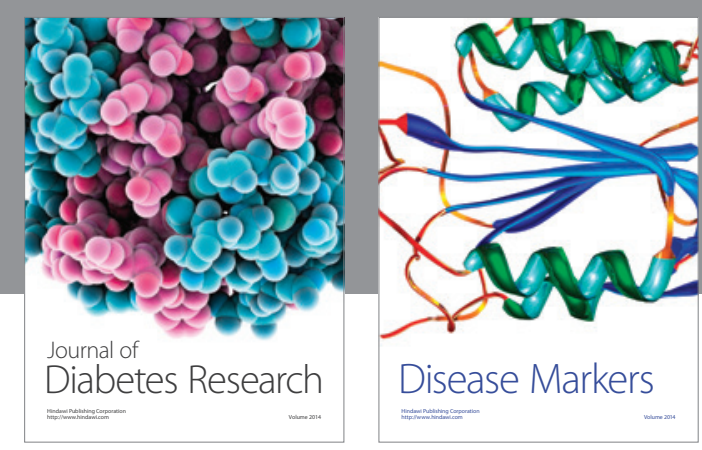

Disease Markers
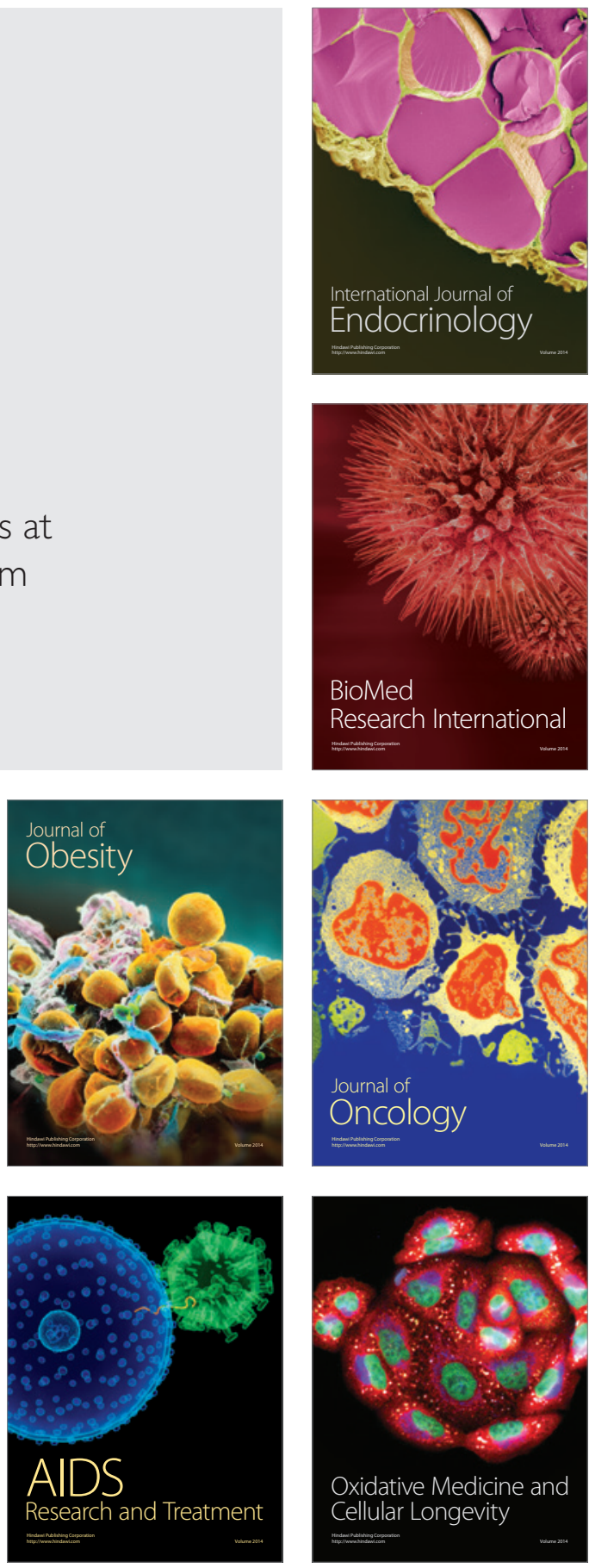